\title{
Uma análise de discursos sobre a leitura presentes no canal "O mundo segundo Ana Roxo"
}

DOI: http://dx.doi.org/10.21165/el.v49i2.2708

\section{Aline Manfrim \\ Luzmara Curcino²}

\section{Resumo}

Neste artigo, empreendemos uma análise de discursos sobre a leitura a partir do que é enunciado no vídeo "Literatura não é literal", dedicado ao comentário da prática de interpretação de textos, disponível no canal do YouTube do blog "O mundo segundo Ana Roxo", professora, filósofa e progressista. Neste vídeo, é atualizada uma série de representações da leitura e dos leitores brasileiros, que analisamos segundo princípios da Análise do Discurso e da História Cultural. Constatamos, na reiteração de certos lugares-comuns sobre a leitura, na generalização do que é afırmado, e na depreciação de dadas práticas e sujeitos, a força de certos consensos histórica e conjunturalmente constituídos e que perduram em relação ao enunciável sobre essa prática e sobre nós como leitores.

Palavras-chave: discurso; leitura; YouTube; literatura.

1 Universidade Federal de São Carlos (UFSCar), São Carlos, São Paulo, Brasil; aline.maria.manfrim@gmail.com; https://orcid.org/0000-0002-9479-9057

2 Universidade Federal de São Carlos (UFSCar), São Carlos, São Paulo, Brasil; luzcf@hotmail.com; https://orcid.org/0000-0003-3555-1446 


\title{
An analysis of reading speeches on the channel " 0 mundo segundo Ana Roxo"
}

\begin{abstract}
In this article, we undertake an analysis of discourses on reading from what is stated in the video "Literature is not literal", available on the YouTube channel "The World According to Ana Roxo". In this post, dedicated to commenting on the practice of interpreting texts, especially those of artistic origin that use figurative language, a series of consensual representations about reading and readers in Brazil are updated, which we describe and analyze according to the principles of Discourse and Cultural History Analysis. We find, in the reiteration of certain commonplaces, in the generalization of what is affirmed and in the depreciation of certain practices and certain subjects, the symbolic force of these historically and conjunctively constituted consensuses, which last in relation to the enunciable about reading and about us as readers.
\end{abstract}

Keywords: discourse; reading; YouTube; literature.

\section{Discursos sobre a leitura e a força do consenso}

Reflexões sobre a leitura são desenvolvidas há muito, por diversos pesquisadores, em diferentes frentes e com distintas finalidades. Esse interesse peculiar sobre essa prática deriva, por um lado, da importância e da frequência de seu uso em uma sociedade com escrita como a nossa, por outro, de sua complexidade. Sua necessidade constante e a variedade dos modos de como exercê-la justificam a proliferação de dizeres a seu respeito, desde os comentários cotidianos às explicações mais sofisticadas. Apesar do volume expressivo do que se enuncia hoje em dia a seu respeito, varia muito pouco o que é efetivamente enunciado (CURCINO, 2018). A força consensual do que se pode e se deve dizer sobre a leitura deriva do funcionamento de uma ordem discursiva (FOUCAULT, 1999) que regula e controla o enunciável, quando somos convocados a falar dela, e que fornece, limita e hierarquiza os argumentos, as recomendações e os julgamentos sobre essa prática.

A constituição histórica desses discursos e sua consolidação no contexto brasileiro remonta a diferentes períodos e uma de suas distintas emergências é abordada por Abreu (2001, 2009), ao comparar uma série de representações de leitores europeus e brasileiros inscritas em imagens (pinturas e fotografias), do século XVIII aos dias de hoje. Ela observa nesse corpus tanto a reiteração idealizada de certas práticas de leitura e de formas de ser leitor, quanto as hierarquias simbólicas que se constituem nas formas de apresentação distintas dos sujeitos nelas representados: europeus e brasileiros; homens e mulheres; ricos e pobres. Ela constata que as formas de julgamento que ainda são atualizadas no presente remontam àquelas do final do século XVIII e começo do século XIX, em que se instituíram como forma ideal de ser leitor as práticas culturais de burgueses europeus. 
Apesar dos séculos transcorridos e das mudanças culturais que relativizaram certas crenças, tanto a imagem idealizada do leitor quanto a hierarquização que ela pressupõe circulam ainda entre nós com valor de verdade, sem levantar muita suspeita ou questionamento, de forma naturalizada, inviabilizando uma outra postura ou visão sobre a leitura.

A representação ${ }^{3}$ do leitor idealizado continua sendo a daquele que vive cercado por livros, que lê frequentemente, não qualquer coisa, mas certos textos de prestígio, sempre em sua totalidade, em geral para ilustração, mesmo quando se trata de textos ficcionais, não se restringindo às leituras com finalidades pragmáticas, impostas pelas urgências do dia a dia. Segundo essa representação, ele é aquele que dedica tempo a essa prática, que a exerce de forma espontânea e prazerosa, que domina o repertório adequado do que merece ser lido e as formas de como opinar apropriadamente sobre o que leu junto a uma dada comunidade de leitura. É aquele, ainda, que compra livros, tem livros, frequenta espaços dedicados a esse objeto (como bibliotecas, feiras culturais, saraus, eventos literários), circula entre outros leitores e se pronuncia sobre essa prática com a propriedade que essa sua condição leitora Ihe outorga. É aquele, enfım, que tem autoridade para retomar o enunciável sobre essa prática e manter e fornecer os modelos do que é adequado dizer quando se deve falar de si como leitor, ou da leitura, ou de outros leitores ou daqueles que considera não leitores ${ }^{4}$.

É em função da força e da estabilidade dessas representações idealizadas do que é ser leitor e das formas legítimas de ler que, quando somos perguntados ou quando é preciso

3 Tal como o discurso, as representações dizem respeito a um conjunto coletivo de crenças, sentidos e valores compartilhados em uma dada sociedade em determinado período histórico. Portanto, elas não são nem individuais nem tampouco universais. Elas "não são simples imagens, verídicas ou enganosas, de uma realidade que lhes seria exterior. Possuem uma energia própria que convence que o mundo, ou o passado, é realmente o que elas dizem que é." (CHARTIER, 2011a, p. 281). Sua "energia" diz respeito não apenas ao poder de mostrar aquilo que representa acerca do mundo social, mas também, e principalmente, de construir esse mundo social. Para o historiador, a representação de uma prática, como a leitura, é tão importante quanto as determinações objetivas, materiais, que regulam essa prática. A identificação (ou não) dos sujeitos com leitura e como leitores depende da incorporação de certas representações a que são expostos em função de sua origem, trajetória e pertencimento. A legitimidade que as representações de certas práticas de leitura adquirem, em detrimento de outras, perpetua certas formas de dominação e de hierarquização dos sujeitos. A compreensão do funcionamento simbólico dessas representações dominantes é decisiva para que sua crítica e suspensão sejam possíveis (CHARTIER, 2011b, p. 9).

4 Acerca dessas e de outras representações do "leitor ideal", conferir Abreu (2001), Britto e Barzotto (1998) e Curcino $(2016,2018)$. 
falar sobre a leitura, acionamos essa memória discursiva ${ }^{5}$ (COURTINE, 1999; 2009) acerca de um leitor fantasmático ${ }^{6}$ (BAYARD, 2007). Essa imagem compartilhada faz com que nossas respostas a essas perguntas tenham como parâmetro aquilo que "sabemos" serem as práticas mais relevantes socialmente, enobrecedoras, declaráveis. É a maior ou menor proximidade e identificação com essa "imagem" que norteia o que devemos/ podemos dizer sobre nós como leitores. É ela que nos impõe o sentimento de orgulho ou de vergonha e culpa em relação a essa prática. É ela que nos faz enunciar de modo orgulhoso nossa condição de leitor, ou de modo envergonhado a culpa por não lermos, por acreditarmos que lemos mal, ou que não lemos o que deveríamos nem do modo tido como mais apropriado, conforme parâmetros que sabemos existir. Esses parâmetros nos chegam com frequência e por isso os reproduzimos sem mensurar seus impactos. Sob a injunção inevitável desses discursos sobre o livro, sobre a leitura e sobre o que é ser leitor, reproduzimos seus valores, nos identificamos com os julgamentos que eles constroem, assumimos os designativos e qualificativos que eles fornecem, nos acomodamos às hierarquias culturais que eles afırmam e nos tornamos vetores de sua difusão.

Tamanha é a força simbólica desses discursos, sua onipresença, seu valor de verdade, que eles são assumidos contraditoriamente tanto por aqueles que deles se beneficiam, quanto e sobretudo por aqueles que deles são vítimas. Isso se dá de tal modo que, para alguns, mesmo sendo leitores, mesmo lendo textos de forma espontânea e relativamente frequente, para entretenimento, informação, aprendizado ou ilustração, mas caso destoem nas escolhas, nas finalidades, nos rituais de apropriação, não são aceitos no "clube" daqueles que se guiam pela imagem dos leitores fantasmáticos. Mais relevante ainda que isso, a força desses discursos faz com que nem eles próprios se reconheçam como pertencendo ao "clube". Compreender esse funcionamento dos discursos pode contribuir, inicialmente, com o rompimento de um ciclo de violência simbólica e de estigmatização, altamente generalizado, naturalizado e institucionalizado em nossa sociedade. Pode também contribuir para atuarmos de modo mais eficaz no enfrentamento das reais e das efetivas razões que inviabilizam, para a maioria de nós, poder vir a ser leitor.

50 conceito de memória discursiva é distinto de toda memorização psicológica [...], diz respeito à existência histórica do enunciado no interior de práticas discursivas regradas" (COURTINE, 2009, p. 105). Trata-se de uma memória coletiva, externa ao indivíduo, anterior historicamente à sua enunciação, e própria à formulação de todo e qualquer enunciado, responsável por seus efeitos de sentido. Todo enunciado, em sua formulação e em sua condição de acontecimento discursivo, estabelece com um já dito, anterior e específico, uma complexa relação, segundo Foucault (2015), de repetição, refutação, transformação, denegação, de modo tanto a ser afetado, em sua condição de enunciado, quanto a afetar, seja reforçando a sua permanência seja alterando esse conjunto anterior do dizível sobre um tema, um acontecimento ou uma prática.

6 Recorrendo ao termo fantasma, comumente empregado na psicanálise, o autor visa caracterizar, em relação à leitura, um tipo de imagem, idealizada e falseadora da realidade, que compartilhamos sobre o que é ser leitor, em função de uma "série de imposições interiorizadas", que incorporamos e que entre outras consequências seria responsável por "uma hipocrisia geral sobre [o que dizemos em relação aos] livros efetivamente lidos" (BAYARD, 2007, p. 15). 
Em consonância com as pesquisas realizadas junto ao LIRE - Laboratório de Estudos da Leitura (CNPq/UFSCar), nos dedicamos à análise de discursos sobre a leitura e sobre o leitor, em especial aqueles relativos à atualidade. Para isso, nos valemos de diferentes textos e fontes, entre eles aqueles que são formulados e que circulam virtualmente, sob a forma de postagens em redes sociais e em canais de plataformas de vídeo. Essa tem se tornado uma fonte não negligenciável para estudos sobre as representações da leitura e dos leitores, uma vez que nesse universo virtual se multiplicaram exponencialmente a produção de enunciados, sob a forma de textos de diferentes gêneros e origens institucionais, de declarações de viés público ou privado, motivadas ou espontâneas.

Dado nosso interesse em comum pela leitura, ou seja, pela análise do que se enuncia a seu respeito na atualidade, conjugado com o acesso ímpar a registros virtuais de diferentes ordens que abordam esse tema, neste artigo apresentamos uma análise do que foi enunciado sobre a leitura em um vídeo publicado via YouTube, intitulado "Literatura não é literal", disponível no canal "O mundo segundo Ana Roxo". A adoção, como corpus, deste objeto específico justifica-se na medida em que, apesar do posicionamento progressista, emancipatório e politizado manifesto em outros temas comentados pelas responsáveis pelo canal, reitera-se neste vídeo uma visão relativamente elitista, beletrista e despolitizada acerca da leitura, em conformidade com os discursos dominantes sobre essa prática e com as representações consensuais que compartilhamos em nossa sociedade. Esse é um exemplo bastante emblemático do funcionamento da "contradição". É também um exemplo de como é mais fácil perceber as desigualdades sociais no âmbito material, e denunciá-las, do que compreender aquelas de ordem simbólica relativas ao âmbito cultural.

Embora desde a década de 60 do século passado, Bourdieu (BOURDIEU, 1999; BOURDIEU; PASSERON, 2011) tenha abordado esse impasse, ao apresentar sua teoria dos capitais (capital cultural, capital social etc.) e ao demonstrar que o capital cultural é fundamental para justificar as desigualdades socioeconômicas, uma vez que tanto o acesso regrado à cultura de prestígio quanto a invisibilidade da força das relações interpessoais das classes privilegiadas fundamentam a "verdade" do discurso meritocrático, ainda assim, sujeitos progressistas e politizados reproduzem, segundo a lógica da dominação, as hierarquias socioculturais que fundam nossa sociedade, de forma naturalizada, contribuindo para a estigmatização daqueles que, por sua condição social, em grande medida, não dispõem do mesmo acesso à cultura tida como de prestígio.

Isso considerado, é preciso lembrar que nosso objetivo não é criticar, sob a forma de "fogo amigo", o canal e suas responsáveis. Para nós, a análise do que enunciam sobre a leitura é fundamental para demonstrarmos a força de consenso do discurso dominante que regula o que se enuncia sobre essa prática, em alguns casos independentemente dos posicionamentos assumidos por enunciadores que se encontrem em polos opostos quanto à visão política, social e ética de mundo. Como parte da sociedade atual, as lentes 
"vermelhas" do comunismo à brasileira não permitem enxergar todas as contradições que nos constituem. $\mathrm{O}$ que foi enunciado no vídeo que analisamos funciona para nós como uma metonímia do que em geral predomina quando o tema é a leitura.

Para a análise deste vídeo, e do que nele se enuncia sobre a leitura, dos modos como o que é enunciado circula e atua entre nós, nos valemos da Análise do Discurso e da História Cultural. No que diz respeito à primeira perspectiva teórica e metodológica, Possenti (2001, p. 25) afirma que a AD pode ser concebida como uma teoria da leitura, na medida em que

[...] aprendemos a nunca ler um texto isoladamente (não se faz análise do discurso de um texto), a nunca ler um texto considerando-se apenas seu material verbal (aprendemos a relacioná-lo a seu "exterior"), a nunca tratar a linguagem como se fosse transparente (aprendemos a supor sempre que a interpretação é um trabalho, já que as palavras não remetem jamais às coisas), a nunca supor que o texto (ou mesmo vários) fornece todas as condições de sua leitura (aprendemos sempre a supor que, mesmo no domínio textual ou até mesmo no do enunciado mais restrito, é necessário acionar mais de um fator relevante - considerar os pressupostos, a intertextualidade...) etc.

Todas essas diretrizes fornecem formas de interpretar de modo mais consequente o funcionamento discursivo próprio de cada texto, de cada enunciado, assim como compreender o processo implicado em todo e qualquer gesto de leitura e interpretação de um texto. Aprendemos a "ler" em AD, assim como podemos, lendo textos que abordam o tema da leitura, depreender os discursos que atuam na determinação do que nesses textos se diz sobre essa prática.

A História Cultural, tal como empreendida por Chartier (1988) acerca das práticas de escrita e de leitura, contribui com essa abordagem discursiva dos textos na medida em que fornece uma reflexão sobre as continuidades e descontinuidades da história da leitura a partir da análise de diversas formas de representação dessa prática: em quadros, em obras literárias ou nas próprias formas como os objetos culturais ligados à leitura as indiciam (pela escolha da fonte, do tipo de ilustração, do suporte etc.). A conjunção dessa abordagem discursiva e das contribuições históricas sobre a leitura nos permite recorrer às diferentes temporalidades que se encontram no que é enunciado sobre essa prática e compreender mais profundamente a força de reprodução desses dizeres ligada tanto à duração, à frequência e à rarefação do que é dito a seu respeito, como também às instituições e às posições sujeito assumidas por aqueles que a enunciam. 


\section{O canal, o vídeo e o tema da leitura}

As responsáveis pelo canal no YouTube dedicam-se a discutir vários temas da atualidade, em geral concernentes à política. O posicionamento que elas adotam na condução desses temas é alinhado à ordem progressista e ao pensamento de esquerda. Inscrito no YouTube, desde 07 de janeiro de 2016, o canal se propõe, na sua descrição, a realizar "explicações simples para assuntos complexos". Ele foi concebido por Ana Roxo, que atua em geral como o rosto e a voz diante da câmera, e Tati Fadel, que em geral intervém como voz off e que dialoga com a primeira, tece comentários, faz algumas precisões e provocações, garantindo o tom espontâneo e "descolado" dos vídeos. Elas mesmas o mantêm financeiramente, quanto à produção regular dos vídeos, definição das pautas, pesquisa, realização e edição, ainda que disponham de eventual apoio obtido graças a seu cadastro no site www.padrim.com.br.

As postagens normalmente são semanais. A partir de 2017, elas se propuseram, além da publicação do vídeo semanal sobre algum tema da atualidade relacionado à política, a postar mais um vídeo adicional na semana dedicado especialmente à poesia. Devido à dinâmica dialógica, reflexiva e lúdica do canal, o tom bem-humorado, a qualidade da voz e do som, elas também disponibilizam os áudios no formato podcast.

O canal atualmente conta com 47.000 inscritos. Seus vídeos têm um número importante de visualizações, que oscilam entre 2.000 a 260.000 acessos. 0 vídeo com maior repercussão intitula-se "Pobre de direita: não seja essa pessoa", com 267.000 visualizações. Normalmente, os vídeos recebem um número expressivo de comentários, em especial aqueles com potencial de polêmica e que abordem uma "treta" (na gíria empregada pelas enunciadoras) que tenha viralizado nas redes. Os vídeos dedicados à leitura, à interpretação de poesia não contam com a mesma repercussão. Isso provavelmente se deve à não polemicidade do que enunciam a esse respeito, justamente porque o que dizem ecoa, ainda que em suas variações, o discurso autorizado, mais frequente, mais naturalizado sobre a leitura, e que coincide, por isso, com o que pensam os seguidores de seu canal.

As idealizadoras do canal são professoras. Ana Roxo é formada em Artes Cênicas pela ECA-USP e cursa graduação em Filosofia na UNICAMP. Tati Fadel cursou Letras na UNICAMP. Apesar de suas especialidades, o canal é uma atividade amadora e sem fins lucrativos. Entre as características do canal, desde o primeiro vídeo, encontra-se seu tom crítico, incisivo, mas em uma linguagem descontraída e bem-humorada em relação a temas da atualidade, com potencial de polêmica ou com polêmica já estabelecida nas redes sociais. Os temas que o canal mais tem priorizado são aqueles relativos à política atual, ao feminismo, à luta de classes, à educação, abordados a partir de um viés politizado, engajado socialmente e progressista. 
A dinâmica de gravação dos vídeos, conforme suas produtoras explicitam, é a de inicialmente selecionar um tema, discutir alguns de seus aspectos a serem abordados e então empreender o registro audiovisual. Embora elaborem um roteiro prévio, as responsáveis declaram se valer frequentemente do improviso, o que contribui pelo efeito de maior espontaneidade, de informalidade, de "bate-papo" ilustrado e bem-humorado que constitui o ethos por elas adotado. Devido às polêmicas referentes ao contexto político partidário brasileiro atual e à radicalização da bipolarização direita e esquerda que se consolidou discursivamente nos últimos anos, o canal postou alguns vídeos que tratam da leitura, não como tema principal, mas como uma das práticas centrais nesse processo de inflação da circulação de textos, de descentralização da origem e da distribuição da informação, de pulverização das formas de verificação da veracidade do que é enunciado, da exploração massiva de fake news como forma de convencimento.

O vídeo intitulado "Literatura não é literal", publicado no dia 14 de setembro de 2017, que conta com um número significativo de 4.536 visualizações até o momento, é um nos quais as autoras desenvolvem mais explicitamente o tema da leitura. Ele foi gravado em um cenário condizente com as representações convencionais de intelectuais, letrados e por isso leitores: Ana Roxo é filmada tendo como pano de fundo uma estante de livros, além de outros símbolos contemporâneos do feminismo, da resistência, da boemia de esquerda, como uma boneca da Frida Kahlo e outra da Amy Whinehouse?

No vídeo são abordados problemas de compreensão do que é enunciado nas redes sociais e como eles colaboram para um tipo de interação mais "rude" que têm se tornado, se não mais frequente, ao menos mais flagrante nas redes sociais. Os equívocos de interpretação de que se ocupam as enunciadoras são atribuídos, em especial neste vídeo, à incapacidade de muitos "brasileiros" de compreender de forma adequada o funcionamento da linguagem literal e da linguagem figurada, em especial, quando se trata de textos de origem artística, literária.

7 Os oito primeiros vídeos postados no canal tinham como pano de fundo um jardim, posteriormente, um mural de madeira. Do nono vídeo em diante consolida-se, ao fundo, o cenário com a estante de livros. Essa é uma representação clássica, há muito empregada, e que tem por efeito o de ancorar o que se enuncia na autoridade dos livros. Tendo em vista a atualidade dessa produção "youtuber", sua desinstitucionalidade, seu caráter informal e amador, seu potencial de meio formador de opinião, a pressuposição de interlocução com um público prioritariamente jovem, observamos que os comentários/intervenções sob a forma desses vídeos têm adquirido um "acabamento" (BAKHTIN, 2006) em comum, relativamente convencional: o de abordar de forma espontânea e bem-humorada, em uma linguagem informal e acessível, temas que em outros meios são em geral abordados de forma grave, séria, ritualizada. 


\section{Elitismo e beletrismo em leitura: uma análise discursiva}

Candido (2011) aborda a leitura de literatura como um direito. Esse seu posicionamento é de extrema importância, em especial em um país em que o próprio acesso ao direito de aprender a ler foi negado a muitos, em que se negligenciou por tempo demais e ainda se negligencia grande parte da sua população, tanto do ponto de vista do ensino de habilidades da leitura específicas, quanto do acesso aos bens culturais de prestígio como o livro e outros objetos impressos e digitais de circulação de textos valorizados culturalmente. As desigualdades que nos são impostas destinam a fruição da literatura, o direito de ser leitor, a apenas um grupo seleto, pequeno e que não sem razão coincide com aquele que detém os meios materiais de acesso aos bens culturais elitizados em nossa sociedade. A literatura que, segundo o autor, deveria ser um bem incompreensível, incontornável e fundamental, do qual não se pode prescindir por satisfazer uma necessidade essencial do ser humano à ficção, à fabulação, assim como o são outros bens como a alimentação e a saúde, serviu e serve ainda como mecanismo de divisão social, de estigmatização de grupos, aos quais primeiro é negado o direito de ser leitor e, mesmo assim, em seguida é cobrado quanto à obrigação de ler e responsabilizado pela não leitura.

Uma certa tradição beletrista, conservadora e elitista, cuja base de apoio é exatamente a distinção cultural, tal como a definiu Bourdieu (2007), encontrou no Brasil solo fértil. Para nossa elite socioeconômica bacharelesca, a leitura é um adorno e o livro um fetiche ${ }^{8}$. o que se diz a seu respeito não necessariamente corresponde às práticas efetivas de todo esse grupo, mas é assumido tanto por essa elite, como forma de se distinguir e de justiçar sua distinção dos demais, como por aqueles que são por ela estigmatizados em matéria cultural, dada a tamanha força consensual dos discursos dominantes sobre cultura, em geral, e sobre a leitura, em específico.

Apesar das mudanças culturais sensíveis, da perda de força de uma certa tradição cultural, do cinismo de nossas elites que nem precisam se esforçar muito para justificar sua distinção alegada, se valendo para isso da leitura, ainda assim essa prática é frequentemente convocada como "carta na manga" em última instância. A classe média e os trânsfugas de classe, beneficiários do acesso à cultura de prestígio, tendem a se defender com essa mesma carta, muitas vezes sem se dar conta de que trabalham no sentido de reproduzir o discurso dominante sobre a leitura, sem a ponderação necessária do caráter elitizante de grande parte do que dizemos sobre ela.

Isso pode ser observado na atualização de alguns enunciados sobre essa prática que emergem na construção argumentativa do vídeo em análise.

8 Cf. Curcino (2018). 


\section{A poesia entre as recomendações do que ler}

Nos vídeos dedicados especificamente à leitura, as produtoras do canal optaram por abordar preferencialmente um conjunto peculiar de textos: aqueles considerados artísticos. O vídeo em análise, como anuncia a produtora, é "só sobre poesia", e a dinâmica de apresentação consistirá na leitura de uma poesia e depois em seu comentário.

A escolha pela poesia, como texto artístico, gênero literário menos popular, de produção mais rarefeita, e comercialmente não muito viável, contribui para que este gênero discursivo ${ }^{9}$ e editorial seja mais elitizado e sua leitura mais distintiva em relação àquela de outros tipos de texto. Essa escolha também responde ao caráter mais institucionalizado desse gênero, em geral lido na escola, na universidade ou em eventos culturais específicos. Sua leitura é também bem mais ritualizada do que a de outros textos. A poesia, diferentemente das narrativas de contos, novelas ou romances, é também concebida para ser lida com voz, em voz alta, ser declamada em uma prosódia peculiar que restitua ao texto as emoções que ele visa produzir no que enuncia. Sua leitura seria mais exigente do que a de outros textos pela especialidade de sua linguagem, pelo caráter menos cotidiano das estruturas linguísticas adotadas e pelo potencial mais polissêmico dessas escolhas, se comparado a outros gêneros. Trata-se, por essa e outras razões, de um texto mais inacessível, cujo ritual peculiar de sua leitura contribui para isso, em especial se considerarmos que a maioria da população não tem tempo de ler, de que o tempo para a leitura como entretenimento é ainda mais escasso, um verdadeiro luxo, e de que ler textos para entretenimento que exigem um investimento interpretativo distinto e um domínio de certos rituais é um privilégio resguardado para poucos. Assim, aqueles que leem por prazer e/ou por ilustração, de modo espontâneo e frequente, esse gênero literário específico, é porque contam com uma condição privilegiada e distintiva dos demais. Mesmo no caso dos trânsfugas culturais, a leitura de poesia, por sua excepcionalidade, autoriza o sentimento de certo orgulho de poder ser esse tipo de leitor, ler esse tipo de texto que o faz diferente da maioria.

O gênero poesia é por vezes referido no vídeo metonimicamente por um tipo de linguagem que equivaleria a seu regime enunciativo geral: a linguagem figurada. As produtoras, a partir desses pressupostos, decidem focalizar sua reflexão na explicação da distinção entre linguagem figurada e literal. Esses pressupostos regulam e explicam o tom e o estilo didático adotados no vídeo na abordagem do tema, e cujo comentário é bastante semelhante às práticas escolarizadas de ensino da leitura (algumas delas criticadas neste mesmo vídeo), uma vez que não se lê o texto, não se prioriza a sua leitura; uma vez que o texto é referido para se ensinar outra coisa, ou seja, que ele "é usado como pretexto" para

9 Bakhtin (2006, p. 261) afirma que "cada enunciado particular é individual, mas cada campo de utilização da língua elabora seus tipos relativamente estáveis", aos quais ele denomina gêneros do discurso. Eles se caracterizam pela regularidade quanto a seu conteúdo temático, estilo verbal e construção composicional. 
lançar luz para a diferença entre linguagem figurada e literal; uma vez que se explica o seu enredo e se apresenta suas personagens de modo genérico, sem uma análise relacionada à forma propriamente adotada na produção do texto (escolhas linguísticas que dão existência às metáforas, ao duplo sentido etc.); uma vez que se explica o outro sentido visado pelo autor, sem se demonstrar pela análise quais marcas no texto autorizam e provocam esse outro sentido; uma vez, enfım, que se emprega, nessa explicação, a terminologia tradicional da metalinguagem explicativa escolar (linguagem figurada e literal, literalidade, gênero, fábula, figurativização, nível de interpretação, metáfora, ironia, símbolo etc.). A diferença essencial de abordagem está na informalidade e leveza com que se quis "ensinar" esse conteúdo, a abertura para o bom humor, o vocabulário jovem, o tom "descolado" adequados sobretudo ao estilo de linguagem própria de vlogs e seu modo de circulação nas redes.

Os textos aludidos pelas produtoras, a título de exemplo de análise para abordar essa condição de plurissignificação não exclusiva da linguagem poética, embora ela seja mais frequente nesse gênero, não são propriamente poemas, mas sim clássicos da cultura contemporânea letrada brasileira e da literatura universal: i) "Os saltimbancos", fábula musical traduzida e adaptada para o português, por Chico Buarque de Hollanda; e ii) "Hamlet", de Shakespeare. Sua escolha revela a partilha de um repertório que, por si só, goza de prestígio cultural em nossa sociedade, tratando-se de textos e autores consagrados, cuja circulação, mesmo no ambiente escolar, é bastante rarefeita, incomum e elitizada. A escolha não é aleatória. Ela se funda nos consensos compartilhados socialmente daquilo que em nossa cultura é prestigioso se apresentar como consumidor.

\section{O "problema" da interpretação de texto no Brasil}

Além da proposta de leitura de textos artísticos, em especial da poesia, a produção desse vídeo é justificada em função do que as enunciadoras chamam da "treta" da semana, que não é precisada, mas que se depreende estar relacionada ao tema do problema de interpretação, uma vez que elas recuperam alguns enunciados coletivos, conhecidos, e que ilustrariam tanto a "treta" quanto o retorno dessas citações: i) "O problema do Brasil é falta de interpretação de texto"; ii) "Falta amor, mas também falta interpretação de texto"; iii) "As pessoas não sabem ler arte".

A justificativa para sua iniciativa, dessa série de vídeos do canal, tem a ver com a representação compartilhada socialmente de que "as pessoas" não leem, não sabem ler, não sabem ler arte, de que "as pessoas não entendem" certos funcionamentos da linguagem de textos artísticos, que ler poesia não é para qualquer um, que a escola, embora ensine a ler/decodificar, não ensina a ler/interpretar poesia. 
(01) Não sabem... nunca souberam, não vai ser agora que vão saber. Estamos aqui contribuindo um pouco para que saibamos... entender umas ironias... A gente vai falar um pouco sobre isso: porque as pessoas não entendem qual é o problema da linguagem em uma rede social. A gente vai falar um pouco sobre linguagem figurada. Qual é a diferença da linguagem literal e da linguagem figurada.

Considerando que todo enunciado projeta os sujeitos "que falam", aqueles "para quem falam", e eventualmente aqueles "de quem falam", observamos o recurso das enunciadoras à generalização, própria ao senso comum, de que "as pessoas não sabem ler", entendendo que por "as pessoas" não se está referindo a qualquer um ou a todo mundo indistintamente, apesar da presença de um "nós" de tipo aparentemente inclusivo, expresso em "saibamos". Essa ocorrência linguística não inclui as enunciadoras, uma vez que o objetivo do vídeo é "suprir" essa carência das "pessoas". Essa generalização "as pessoas" refere-se a um sujeito coletivo impreciso. Pela forma como argumentam, é possível excluir as enunciadoras, mas também os sujeitos para quem elas falam. Por mais estranho que isso pareça, por se tratar de um vídeo dedicado a contribuir com a formação leitora de espectadores que não dominam o pronto reconhecimento de certos usos especializados da linguagem (como a ironia), estes não são, ou ao menos não majoritariamente, o público de seguidores do canal. Estes últimos são representados no vídeo como interlocutores que compartilham, se não de todas as referências culturais de prestígio, ao menos de grande parte daquelas mencionadas por suas produtoras.

Não sem razão, Ana Roxo se refere, ao iniciar a explicação do que designam o "caminho das pedras", um "caminho de leitura", que vai se valer de "um exemplo bastante básico, um exemplo bem básico, que faz parte de nossa infância: "Os saltimbancos". A própria qualificação do texto referido como "exemplo bastante básico" indicia a pressuposição de aspectos do perfil leitor daqueles que são seus seguidores. A qualificação "bastante básico" atribuída à escolha de "Os saltimbancos" como exemplo de texto a ser abordado indicia por parte da enunciadora a antecipação de eventuais críticas de seus seguidores que, como leitores letrados, dispõem de um repertório de leitura considerável e elitizado.

Tanto essa qualificação quanto a localização da leitura desse texto no tempo de infância visam assegurar uma recepção mais compassiva por parte de sujeitos conhecedores desse e de outros textos de mesmo gênero, ou se dirige a sujeitos que se identifiquem em relação à partilha comum, desde a infância, dessa referência cultural citada. O público do qual falam (que não sabem ler) não é o mesmo daquele para quem falam (e para quem é "bastante básico" ter lido "Os saltimbancos"). O público de que falam é aquele que não lê e não sabe ler poesia, ou ao menos não sabe ler linguagem artística e certas especificidades dela, como a sua não literalidade. O público de que falam é aquele que não entende ironia, daquelas comuns em textos que circulam em redes sociais. Isso exclui, contraditoriamente, o público a que se dirigem, ao mesmo tempo em que adotam em relação a ele essa postura didática de ensinar a ler adequadamente. Essa contradição, 
ou ambiguidade, resulta da relação complexa entre as representações generalizadoras, dominantes, do senso comum sobre a leitura e sobre os leitores no Brasil (não sabem ler) com a interlocução efetiva com um grupo de leitores, que compartilham inclusive as mesmas referências culturais que as responsáveis pelo vídeo.

Essa representação recorrente e genérica de que os brasileiros não leem, não sabem ler, não gostam de ler é analisada por Márcia Abreu (2001, 2009), que identifica um dos contextos de emergência desse tipo de "verdade" sobre nós. Ela analisa o papel dos relatos de viagem, escritos sobre nosso país, no século XVI, pelo olhar europeu dos viajantes que aportaram por aqui, e uma série de outras representações tributárias do contexto europeu do século XIX, e encontra no material analisado o eco dessas representações difusas e comuns, constantes e atualizadas ainda hoje acerca do leitor brasileiro. Esses relatos e essas representações atuaram como uma fonte de constituição da nossa identidade cultural. O tom depreciativo que adotaram em relação aos leitores brasileiros, a uniformidade nesses documentos em suas avaliações etnocêntricas que empreenderam, as desigualdades no modo como avaliaram a vida letrada nacional, apresentando-a como degradada, desinteressante e inadequada, se comparada com a prática na Europa, é reatualizada nessas generalizações que nos são contemporâneas. Assim, os consensos sobre a leitura que testemunhamos circular hoje em dia foram em grande medida constituídos nesse cenário histórico, a partir desse olhar externo ou interno que comparava a Europa ao Brasil, sempre em benefício da primeira e em prejuízo para o segundo.

Uma das formas mais atualizadas desse discurso, é aquela segundo a qual "Falta amor no mundo. Mas também falta interpretação de texto". Trata-se da citação da postagem que o jornalista Sakamoto fez em dois momentos, uma em 2013, em seu mural do Facebook, e outra em 2016, um ano antes da postagem do vídeo analisado.

Figura 1. Postagem na página do Facebook em 2013

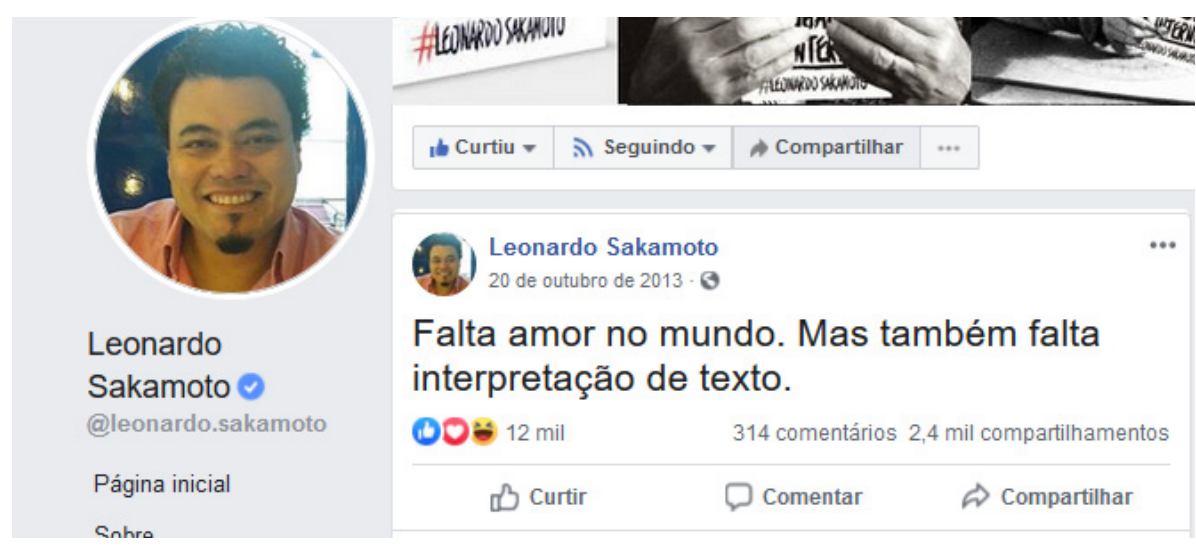

Fonte: Print da rede social do autor 
Essa postagem foi realizada quatro meses após as manifestações que ocorreram em maio de 2013 no Brasil, com o propósito inicial de protestar contra o aumento das passagens do transporte público no estado de São Paulo, mas que prontamente foram recuperadas pelas elites e pela mídia tradicional a seu serviço, reorientando e conduzindo o escopo dos protestos para as ações do governo federal de Dilma Rousseff. A instrumentalização do movimento, por meio da produção e da interpretação de textos pela mídia, foi responsável pela "federalização" dos protestos e pela crescente onda de manifestações de direita e de extrema direita no país. Em 2016, o autor retoma o mesmo enunciado, dessa vez relativo a um caso bem específico:

Figura 2. Postagem no jornal GGN, em 2016
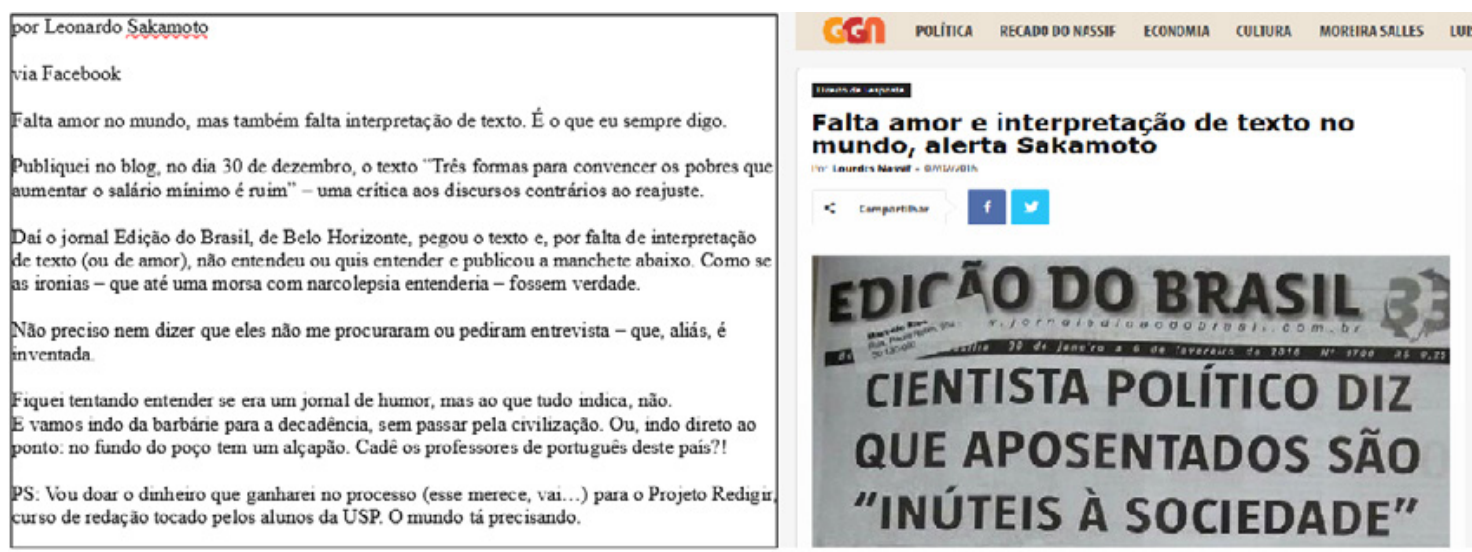

Fonte: https://jornalggn.com.br/direito-de-resposta/saka/

Nessa postagem de 2016, no GGN, Sakamoto, também de forma irônica, afırma que seu texto foi recuperado pelo jornal "Edição do Brasil" e teve seu sentido alterado "seja por falta de interpretação de texto (ou de amor)". Ao retomar esse enunciado, que se tornou uma espécie de "bordão" nas redes sociais, Ana Roxo adere ao que ele afırma, ratifica seu caráter genérico e o intensifica ao afirmar "não sabem, nunca souberam, não vai ser agora". Por se alinharem politicamente, tanto Sakamoto quanto Roxo, nesse enunciado em que afirmam faltar interpretação de texto no Brasil e no mundo, não estão se referindo a todos, indistintamente, mas a uma parcela da sociedade brasileira ou mundial: seja a parcela daqueles que exploram essa dificuldade de leitura que se pressupõe da parte de muitos brasileiros, seja a parcela que é refém desse mecanismo de exploração e que diante dos tipos de texto que circulam massivamente não é capaz de lhes interpretar em sua efetiva "intenção", em seus "duplos sentidos" e em sua "ironia". 


\section{0 papel da escola na interpretação de textos}

Para todo problema busca-se um culpado. Em relação à leitura, à formação de leitores, os culpados são sempre os mesmos: os pais que não leem; a escola que não ensina; os indivíduos que não se interessam. Apesar de toda a reflexão realizada nos anos 80 no Brasil acerca dos empecilhos materiais e socioeconômicos que atuam como condição para se "poder ser leitor", ainda são consensuais os discursos do "dever ser leitor" e da responsabilização ideologicamente perversa dos indivíduos, em especial daqueles que por sua origem estão fadados à não-leitura e ao estigma de não-leitor. No vídeo em análise, embora produzido por professoras engajadas socialmente, comprometidas com o bem-estar social da maioria, altamente esclarecidas, vemos ser reproduzida essa crítica dirigida à ação de certos indivíduos e a uma instituição: os professores e a escola.

(02) Não existe um espaço na escola em que a gente aprenda uma forma de ler? É como se fosse um pressuposto que a partir do momento em que você aprende a decodificar as letras, palavras e frases isso já é ler quando a leitura tem um conjunto de fatores que são necessários para que ela seja feita. Não é só decodificar. É pouco só falar o significado das palavras. É, tem mais que isso, tem a percepção dos usos que você faz da linguagem e das situações em que você usa. Isso em geral não é abordado né, porque todo professor dá como pressuposto que todo mundo já sabe ler.

Essa forma como a autora escolhe atribuir sentidos à escola remete aos discursos que tornam essa instituição e seus membros o bode expiatório para todos os problemas do ensino/aprendizado. Esta forma de compreensão remete diretamente às escolas públicas e as invalida, novamente de forma generalizante, porque nela não se abordariam questões mais profundas acerca da leitura. Assim, não há por parte do vídeo a articulação-denúncia entre as críticas que são expressas acerca da incapacidade da escola e dos professores de ensinar a ler certos textos, com a política sistemática de estrangulamento e crise dessas instituições por parte do poder das elites, com as condições socioeconômicas das famílias dos alunos, com a classe social a que pertencem e a relação necessária dessas condições com o acesso precoce e qualitativo à leitura e às práticas letradas de prestígio.

Apesar do posicionamento igualitarista, progressista e de esquerda assumido na maioria dos vídeos sobre os diferentes temas neles abordados, ao se falar da leitura há um "esquecimento" das condições materiais decisivas para que se possa ser leitor e do funcionamento da ideologia dominante no que diz respeito à apropriação do capital cultural de prestígio como justificativa da dominação.

Tanto a representação estereotipada e generalizante dessa escola "que não ensina a ler", que se traduz entre as tantas críticas simplistas dessa instituição ignorando em geral suas condições de funcionamento, quanto a afırmação genérica de que o brasileiro 
não sabe ler, ou ao menos não sabe compreender textos que se valham de figuras de linguagem mais complexas, como os textos poéticos, compõem o rol de enunciados consensuais, repetidos a esmo, abstratos, baseados em impressões sistematicamente difundidas, com um dado conhecimento empírico das atividades empreendidas na escola, mas apresentado de forma generalizada e sem a contrapartida crítica do sistema de precarização da escola, da profissão docente, das condições materiais das famílias, da falta de tempo do trabalhador etc.

\section{Algumas considerações}

As recomendações virtuais de leitura oferecidas pelas enunciadoras do canal em questão tanto representam-nas como leitoras ideais, assim como a seus interlocutores potenciais ou idealizados. Eles atendem aos requisitos de um imaginário elitista de erudição (ter livros, ler livros, ter acesso a elementos prestigiados da cultura, vivenciar práticas de letramento de prestígio deste a escolarização, ler os clássicos, ler teorias fundadoras de discursividade e que forneçam as formas adequadas de se expressar sobre a leitura). No entanto, como mote para justificar o objetivo do vídeo de promover a importância da leitura e de ensinar algumas técnicas para se ler adequadamente certos textos, as enunciadoras responsáveis pela produção do vídeo elegem, em contraponto a elas e a parte de seus interlocutores, todos aqueles que não sabem ler corretamente, ou seja, não sabem compreender usos mais complexos, metafóricos da linguagem empregada em alguns textos. A representação destes últimos como aqueles que não sabem ler e a adoção de um tom didático nesses vídeos auxiliam na composição, por parte das enunciadoras, de um auto-ethos letrado. A interlocução com esses leitores frágeis é antes um simulacro. Eles não são o público a quem prioritariamente se endereçam. Ao mobilizarem essa representação crítica das carências, faltas de certos leitores, as enunciadoras atualizam discursos sobre a leitura comuns, duradouros e distintivos dos sujeitos.

Há, nessa forma de argumentar, a instauração de uma distância entre leitores e não leitores, e de autoidentificação como leitor que se autoriza por isso a empreender a crítica do outro, do não-leitor. Esse distanciamento aludido resulta de consensos generalizantes sobre a leitura, ao mesmo tempo que os reforça. A força desses consensos define o horizonte do que pode e deve ser enunciado sobre a leitura (ler sempre, ler clássicos, ler gêneros de prestígio, ler de forma adequada esses gêneros, compreender o funcionamento das linguagens especializadas e suas figuras). Isso produz a invisibilidade ideológica das condições sociais da leitura e bloqueia o tratamento politizado da questão, mesmo por parte de sujeitos bem formados, altamente politizados, alinhados à esquerda que compartilham de uma visão materialista do funcionamento da sociedade e das relações entre os sujeitos. Nesse sentido, todo o trabalho de exemplificação e explicação técnica sobre a linguagem figurada não parece ser efetivamente dirigido para um público de não-leitores, para esclarecer-lhes quanto a existência e usos da linguagem figurada nos textos. Esse trabalho não parece estar destinado aos que elas sinalizam como nãoleitores, mas antes para manter a conexão ideológica entre seus pares, felizes com sua condição privilegiada de leitores. 
Por isso, é preciso sempre considerar que não se pode tornar a prática de leitura uma questão meramente de interesse e competência individual apagando, assim, a força das condições materiais e simbólicas que distribuem os papéis a serem exercidos pelos sujeitos, em função de sua origem social, e com isso reproduzir esse princípio perverso e em geral invisível em suas intenções e consequências da "meritocracia", da "meritocracia cultural" da "meritocracia em leitura". Por isso, cabe a todo educador refletir sobre as razões históricas que reiteram a distinção cultural e assumir com isso uma postura mais comprometida com a transformação social, legando aos outros a reflexão sobre o direito de serem leitores e sobre as formas de dominação material e simbólica que inviabilizam esse devir. Essa tarefa não cabe apenas à escola, embora principalmente a ela. Ela também pode ser exercida por formadores de opinião, como as responsáveis pelo canal de vídeos em questão, e por outros formadores de opinião como elas, que, espontaneamente, de forma criativa, descontraída, em linguagem simples e agradável, possam apresentar o que de fato importa para que a leitura não seja um privilégio de classe, mas sim uma prática emancipadora, enfım, um direito.

\section{REFERÊNCIAS}

ABREU, M. Apatia, Ignorância e Desinteresse - Uma história da leitura no Brasil? Revista Desenredo, v. 2, n. 1, p. 83-98, ago. 2009. Disponível em: http://seer.upf.br/index.php/rd/ article/view/501. Acesso em: 15 set. 2019.

ABREU, M. Diferentes formas de ler. In: XXIV Congresso Brasileiro de Ciências da Comunicação, Intercom, Campo Grande, 2001. Disponível em www.unicamp.br/iel/ memoria/ensaios. Acesso em: 14 set. 2019.

BAKHTIN, M. M. Os gêneros do discurso. In: BAKHTIN, M. M. Estética da criação verbal. São Paulo: Martins Fontes, 2006. p. 261-306.

BAYARD, P. Como falar dos livros que não lemos? Rio de Janeiro: Objetiva, 2007.

BOURDIEU, P. A Distinção: crítica social do julgamento. São Paulo: EDUSP; Porto Alegre: Zouk, 2007.

BOURDIEU, P. Os três estados do capital cultural. In: NOGUEIRA, M. A.; CATANI, A. (org.). Escritos de educação. Petrópolis: Vozes, 1999. p. 71-79.

BOURDIEU, P.; PASSERON, J. J. A Reprodução - elementos para uma teoria do sistema de ensino. Rio de Janeiro: Vozes, 2011. 
BRITTO, L. P. L.; BARZOTTO, V. H. Promoção X Mitificação da Leitura. In: BRITTO, L. P. L.; BARZOTTO, V. H. Em Dia: Leitura \& Crítica. Campinas: Associação de Leitura do Brasil, 1998.

CANDIDO, A. O direito à literatura. In: CANDIDO, A. Vários Escritos. 5 ed. Rio de Janeiro: Ouro sobre Azul/ São Paulo: Duas Cidades, 2011. p 167-191.

CHARTIER, R. Uma trajetória intelectual: livros, leituras, literaturas. In: ROCHA, J. C. C. (org.). A força das representações: história e ficção. Chapecó: Argos, 2011a. p. 21-53.

CHARTIER, R. Defense et illustration de la notion de représentation. In: Working Papers des Sonderforschungsbereiches. n. 640, 2/2011b. Disponível em: http://edoc.hu-berlin.de/ series/sfb-640-papers/2011-2/PDF/2.pdf. Acesso em: 08 maio 2020.

CHARTIER, R. A história cultural entre práticas e representações. Tradução Maria Manuela Galhardo. Lisboa: Difusão Editora, 1988.

COURTINE, J. J. Análise do discurso político: o discurso comunista endereçado aos cristãos. São Carlos: EDUFSCar, 2009.

COURTINE, J. J. O chapéu de Clémentis: observações sobre a memória e o esquecimento na enunciação do discurso político. In: INDURSKY, F.; FERREIRA, C. L. (org.). Os múltiplos territórios da Análise do discurso. Porto Alegre: Sagra Luzzatto, 1999. p. 15-22.

CURCINO, L. Divisões e representações sociais de leitores no Brasil: uma análise de discursos da mídia sobre as práticas de leitura de políticos brasileiros [Relatório Científico de Pós-doutorado 2016-2018 UNICAMP- Campinas / UVSQY-VersaillesFrança]. mimeo, 2018.

CURCINO, L. Discursos hegemônicos sobre a leitura e suas formas de hierarquização dos leitores. In: CURCINO, L.; SARGENTINI, V.; PIOVEZANI, C. (org.). (In)Subordinações contemporâneas: consensos e resistências nos discursos. São Carlos: EDUFSCar, 2016.

FOUCAULT, M. A arqueologia do saber. Rio de Janeiro: Forense Universitária, 2015.

FOUCAULT, M. A ordem do discurso: Aula inaugural no Collège de France, pronunciada em 2 de dezembro de 1970. São Paulo: Edições Loyola, 1999. 
POSSENTI, S. Sobre a leitura: o que diz a análise do discurso? In: MARINHO, M. (org.). Ler e navegar. Campinas: Mercado de Letras / ALB, 2001. p. 19-30.

SAKAMOTO, L. 2013: O ano que ainda não terminou. Disponível em: https:// blogdosakamoto.blogosfera.uol.com.br/2015/09/14/2013-o-ano-que-ainda-naoterminou/. Acesso em: 15 set. 2019. 